\title{
Novel process integration for biodiesel blend in membrane reactive divided wall (MRDW) column
}

\author{
Vandana Sakhre $^{1 *}$, Sanjeev Jain ${ }^{1}$, Vilas S. Sapkal ${ }^{2}$, Dev P. Agarwal ${ }^{3}$ \\ ${ }^{1}$ Madhav Institute of Technology \& Science, Gwalior-474005, India \\ ${ }^{2} S G B$ Amravati University, Amravati-444062, India \\ ${ }^{3}$ Ex Professor, IIT, New Delhi-110001, India \\ "Corresponding author: e-mail: vssakhre@gmail.com
}

\begin{abstract}
The paper proposes a novel process integration for biodiesel blend in the Membrane assisted Reactive Divided Wall Distillation (MRDW) column. Biodiesel is a green fuel and grade of biodiesel blend is B20 (\%) which consist of $20 \%$ biodiesel and rest $80 \%$ commercial diesel. Instead of commercial diesel, Tertiary Amyl Ethyl Ether (TAEE) was used as an environment friendly fuel for blending biodiesel. Biodiesel and TAEE were synthesized in a pilot scale reactive distillation column. Dual reactive distillation and MRDW were simulated using aspen plus. B20 (\%) limit calculation was performed using feed flow rates of both TAEE and biodiesel. MRDW was compared with dual reactive distillation column and it was observed that MRDW is comparatively cost effective and suitable in terms of improved heat integration and flow pattern.
\end{abstract}

Keywords: biodiesel, divided wall column, membrane separator, trans-esterification.

\section{INTRODUCTION}

Increased greenhouse-gas emission and oil prices leads for the development of renewable-energy sources. Biodiesel as green, renewable and sustainable fuel is the promising one towards this development. Biodiesel production using transesterification has been reported since last decade for both homogeneously catalyzed and heterogeneously catalyzed reactions. Biodiesel synthesis using reversible transesterification requires excess methanol in the feed stream. A continuous flow reactive distillation to reduce the excess methanol can be used ${ }^{1}$. Synthesis of biodiesel is costly as compared to conventional fuel, but this can be reduced, to some extent, by the use of heterogeneous catalyst such as mixed oxides of zinc and aluminum ${ }^{2-3}$. Biodiesel synthesis using membrane reactor was also reported recently as the promising technique which can efficiently improve the selectivity and yield. Critical review of membrane reactor and its operation, performance, prospects, challenges, biodiesel refining technology and membrane biodiesel using various processes is reported ${ }^{4}$. Biodiesel production using the hybrid techniques such as reactive distillation as the thermally efficient process is also reported by many researchers. Transesterification by the combination of reactive distillation and pervaporation is used to increase yield and purity of the biodiese ${ }^{5-7}$. Experimental synthesis using continuous flow reactor and optimization of various experimental conditions such as a feed molar ratio, reaction time, reboiler temperature and catalyst concentration has been carried out ${ }^{8-9}$. Transesterification in reactive distillation is advantageous for various reasons: such as it is beneficial due to its ability to save energy as compared to conventional process and process integration provides an alternative scheme which is capable of maintaining a temperature profile of the column. Controlled stage temperature shows no multiplicity, and proper temperature control can maintain reactant inventory ${ }^{10-16}$. Biodiesel synthesis using the energy-efficient techniques such as using Divided Wall Column (DWC), which is the practical implementation of Petlyuk column, is developed and reported extensively ${ }^{17}$. Energy efficient extractive and azeotropic distillation using thermally intensified reactive divided wall column proves not only in energy saving, but also an effective technology for reducing operating and equipment $\operatorname{cost}^{18-20}$. Simulation studies for biodiesel production using methanol at higher temperature and pressure which is beneficial in reducing energy, cost of production and emission of pollutant has been proposed ${ }^{21-22}$. Thermally coupled RDC simulation and optimization studies have also been proposed ${ }^{23-24}$.

Research studies on biodiesel production using various techniques has been proven to be environmental friendly fuel when blended with petroleum diesel. Industries believe that blending of biodiesel up to $20 \%$ (B20) causes no detrimental effects on performance of the engine. Greater than $20 \%$ blends may influence on cold flow properties, fuel stability, biological growth, energy content and overall handling. Fluctuation of petroleum diesel prices and the depletion of petroleum resources increases interest in the development of alternative fuel. No alternative fuel which can replace petroleum diesel throughout the literature has been reported. Tertiary Amyl Ethyl Ether (TAEE) has been proven to be an alternative future fuel. Octane number is an expression for the antiknock property of biodiesel, which can be increased by adding a certain percentage of oxygenates. TAEE is an excellent oxygenate of the ether family because of its non carcinogenic nature and availability of raw material as the byproduct of other industrial processes.

In this research work we have developed a novel membrane assisted reactive divided wall (MRDW) process for biodiesel production using the transesterification process. Zeolite is used as the membrane act as a divided wall between two reactive distillation's processes, which allows common reactant ethanol to pass through it. Then we have used dual process integration technique to produce biodiesel and TAEE simultaneously, in reactive distillation, from which both biodiesel and TAEE is send to a mixer to blend biodiesel with TAEE. Both the techniques, i.e. MRDW and dual reactive distillation were simulated and compared. Simulation studies show TAEE and biodiesel flow rate of $116.20 \mathrm{~kg} / \mathrm{hr}$ and 28.3 
$\mathrm{kg} / \mathrm{hr}$ respectively with final oxygen percent of $2.7 \%$ in the product blend gives biodiesel blend of $19.7 \%$, which is within B20 limit. The organization of the paper is as follows: after a brief introduction, section 2 describes the methodology under which we also give details of process description of biodiesel synthesis, TAEE synthesis and biodiesel blend, splash blending, dual reactive distillation integration technique and membrane reactive divided wall technique for biodiesel blends. Section 3 describes results and discussion. Section 4 presents the conclusion from the study.

\section{METHODOLOGY}

\section{Process description}

\section{Biodiesel synthesis process}

Transesterification is the chemical process of converting one ester, in this case, the glycerol esters that constitute vegetable oils, into another ester such as the alkyl monoesters that compose biodiesel. This process occurs by reacting the vegetable oil with alcohol in the presence of an alkaline or acidic catalyst as per the following reaction:

$3 \mathrm{ROOH}+3 \mathrm{ROH} \rightarrow 3 \mathrm{ROOR}+\mathrm{H}_{2} \mathrm{O}$

Fatty acid + Alcohol $\rightarrow$ Alkyl ester + Water

However, using methanol as an alcohol poses some problems and limitations in the process. Methanol inhibits the reaction due to the presence of water and produce free fatty acids and soap. The suitable alternative is to use ethanol instead of methanol. Ethanol is very much less toxic than methanol, and is readily available from the fermentation of corn. The reaction chemistry of biodiesel synthesis using ethanol and fatty acids presents in vegetable oil is shown below:

$3 \mathrm{ROOH}+3 \mathrm{ROH} \rightarrow 3 \mathrm{ROOR}+\mathrm{H}_{2} \mathrm{O}$

Fatty acid + Ethanol $\rightarrow$ Alkyl ester + Water

The kinetic model is given as:

$r=m_{\text {cat }}\left(k_{1} * x_{B D} * x_{\mathrm{H} 20}-k_{2} * x_{F A} * x_{E t O H}\right)$

$\mathrm{k}_{1}=\mathrm{k}_{1}^{0} \exp \left(-\mathrm{E}_{1} / \mathrm{RT}\right)=3.4 \times 10^{10}$

$\mathrm{k}_{2}=\mathrm{k}_{2}{ }^{0} \exp \left(-\mathrm{E}_{2} / \mathrm{RT}\right)=8.3 \times 10^{10}$

$\mathrm{E}_{1}=13.14, \mathrm{E}_{2}=6.20$

Where, $\mathrm{m}_{\text {cat }}$ is the mass of catalyst, $\mathrm{T}$ is temperature, $\mathrm{K}, \mathrm{R}$ is universal gas constant $=8.314 \mathrm{~J} / \mathrm{gmmol}^{0} \mathrm{k}, \mathrm{E}_{1}$, $\mathrm{E}_{2}$ are the activation energy, $\mathrm{Kcal} / \mathrm{mole}, \mathrm{k}_{1}{ }^{0}, \mathrm{k}_{2}{ }^{0}$ are the standard rate constant, $\mathrm{L}$ mole/sec.

\section{TAEE synthesis process}

It stands for tertiary amyl ethyl ether. It is an excellent blending component due to its low volatility, high octane number and also that they do not contain aromatic and olefins, when formed by etherification reaction of tert amyl alcohol and ethanol in the presence of an acidic catalyst which may be either homogeneous or heterogeneous in nature.

The chemical reaction and kinetic is shown below:

$\mathrm{TAA}+$ Ethanol $\rightarrow$ TAEE + Water

$2 \mathrm{C}_{5} \mathrm{H}_{12} \mathrm{O}+\mathrm{C}_{2} \mathrm{H}_{5} \mathrm{OH} \rightarrow 2 \mathrm{C}_{6} \mathrm{H}_{14} \mathrm{O}+\mathrm{H}_{2} \mathrm{O}$

The kinetic model is given as:

$r=m_{\text {cat }}\left(k_{1} * x_{T A E E} * x_{\mathrm{H} 20}-k_{2} * x_{T A A} * x_{E t O H}\right)$ where

$\mathrm{m}_{\text {cat }}$ is the mass of catalyst,

$\mathrm{k}_{1}=\exp (15.189-6597.3 / \mathrm{T})$

$\mathrm{k}_{2}=\exp (14.490-6372.9 / \mathrm{T})$.

$\mathrm{T}$ is temperature, $\mathrm{k}_{1}$ is forward rate constant, kgmole/ sec, $\mathrm{k}_{2}$ is backward rate constant, kgmole/sec, $\mathrm{x}$ is concentration of components.

The above process synthesis was carried out in pilot scale reactive distillation column.

\section{Experimental set up}

The experiment was performed in pilot scale packed Reactive Distillation Column (RDC) at an ambient pressure. The internal diameter of the column is $50 \mathrm{~mm}$, and the total height of the column is $3 \mathrm{~m}$. The RDC consists of total seven subsections among these four sections are $50 \mathrm{~cm}$ long, and two sections are each $30 \mathrm{~cm}$ long and, one section is $40 \mathrm{~cm}$ long. Each section (rectifying section, reactive section and stripping section) of the column is $1 \mathrm{~m}$ height. The non-reactive sections (rectifying and stripping) of the column are packed with non-catalytic HYFLUX (Evergreen Ltd., Mumbai). HYFLUX is high efficiency, and low pressure drop wire mesh distillation packing made up of stainless steel 304 and 316. The reactive section is packed with KATAPAK-S (Sulzer Ltd., Switzerland) steel wire mesh packing. KATAPAK-S (S implies sandwich) is a structured catalyst support for use in the gas-liquid reaction system in which catalyst granules can be embedded. KATAPAK-S is immobilized between two sheets of metal wire gauze, forming sandwiches. Each of these sheets is corrugated resulting in a structure with flow channels of a defined angle and hydraulic diameter. Catalyst particles are filled inside the sandwich. The solid catalyst selected for this RDC is Amerlyst-15 (acidic ion-exchange catalyst). The heat input is through a heating mantle which acts as a reboiler. The Reboiler is mounted on the bottom of the column while, the condenser is fitted on the top of the column. The capacity of the Reboiler is 2 litre. The column is equipped with calibrated thermocouples and Rota meter at various locations along the length of the column. The pictorial view of the Reactive Distillation Column (RDC) which is shown in Figure 1. Table 1 gives details on the characteristics of the packed reactive distillation column.

The catalyst used in this study is Amerlyst-15 (solid catalyst). This catalyst is suitable for esterification and transesterification reactions and also, it is having following characteristics:

a) hydrogen concentration of active sites: $\geq 1.7 \mathrm{eq} / \mathrm{L}$; $\geq 4.7 \mathrm{eq} / \mathrm{kg}$,

b) moisture holding capacity: 52 to $57 \%\left(\mathrm{H}^{+}\right.$form $)$

Table 1. Characteristics of packed reactive distillation column

\begin{tabular}{|l|c|}
\hline Contents & Characteristics and conditions \\
\hline No. of stages & 10, including reboiler \& condenser \\
\hline Rectifying section & $7-8$ \\
\hline Reactive section & $3-6$ \\
\hline Stripping section & $1-2$ \\
\hline Packing used & HYFLUX \\
\hline Catalyst & Amberlyst-15(Acidic ion exchange) \\
\hline Catalyst granularity & $7.4 \times 10^{-4}$ \\
\hline Average particle & 0.99 \\
Diameter [m] & 0.32 \\
\hline Apparent density $\left[\mathrm{g} / \mathrm{cm}^{3}\right.$ ] & Total condenser \\
\hline Macro porosity of catalyst & \\
\hline Condenser type &
\end{tabular}




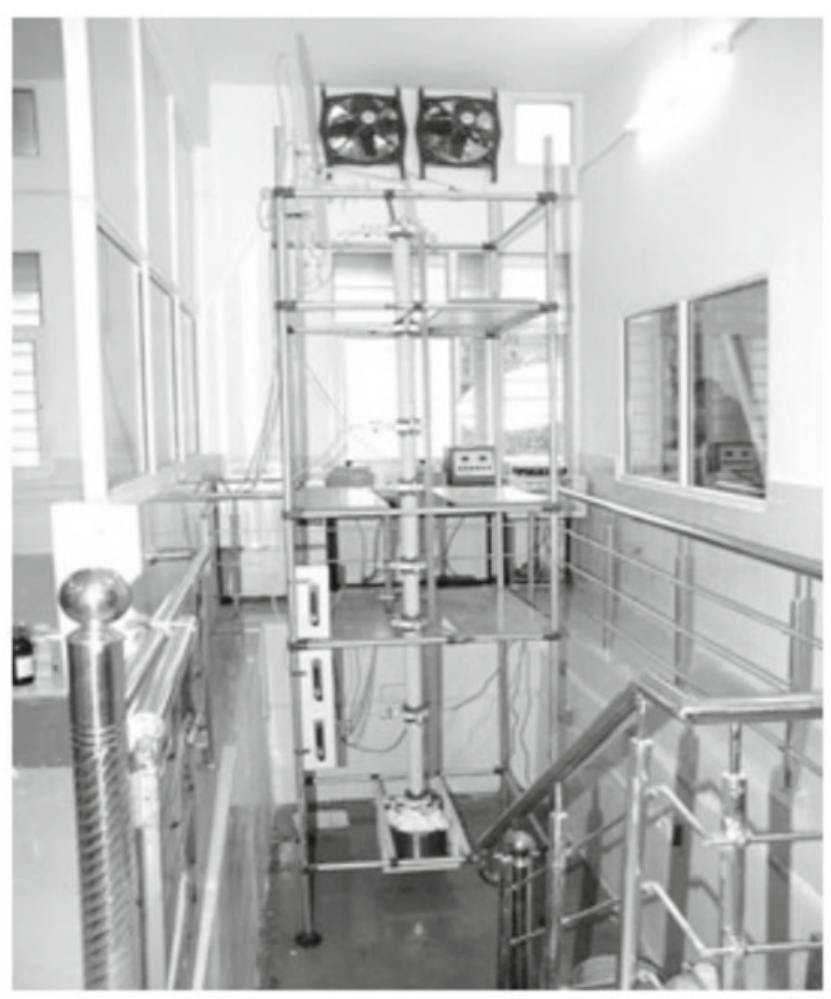

Figure 1. Pictorial view of pilot scale reactive distillation column

c) shipping weight: $770 \mathrm{~g} / \mathrm{L}$,

d) particle size: 0.600 to $0.850 \mathrm{~mm}$,

e) average pore diameter: $300 \AA$,

f) total pore volume: $0.40 \mathrm{~mL} / \mathrm{g}$,

g) maximum operating temperature: $120^{\circ} \mathrm{C}\left(250^{\circ} \mathrm{F}\right)$.

Amberlyst- 15 as catalyst is used because, it is mild and has highly selective properties, combined with its environmentally benign character and commercial availability. This catalyst gives the maximum conversion of almost $100 \%$ in case of biodiesel production and therefore, we have used this catalyst for this study.

\section{Biodiesel blend process}

Biodiesel is extracted from domestic, renewable resources such as vegetable oil. It is filtered and cleaned to be used as a fuel. The term 'biodiesel' refers to the pure, unblended fuel and is referred to as B100 $(100 \%)$. Blended biodiesel is graded as per the percentage of the blend, for example, a $20 \%$ oxygenate blended biodiesel is graded as B20. Higher than B20 (\%) biodiesel blends may require equipment modifications because, diesel Particulate Matter (PM) is high and exposure of such PM to humans is dangerous. In this work, B20 (\%) biodiesel and TAEE oxygenate were blended and used as fuel for testing.

This research work explores various methods for blending of biodiesel using TAEE fuel oxygenate. Figure 2 (part 1) describes conventional and mostly used splash blending. Dual RD integration technique is shown as

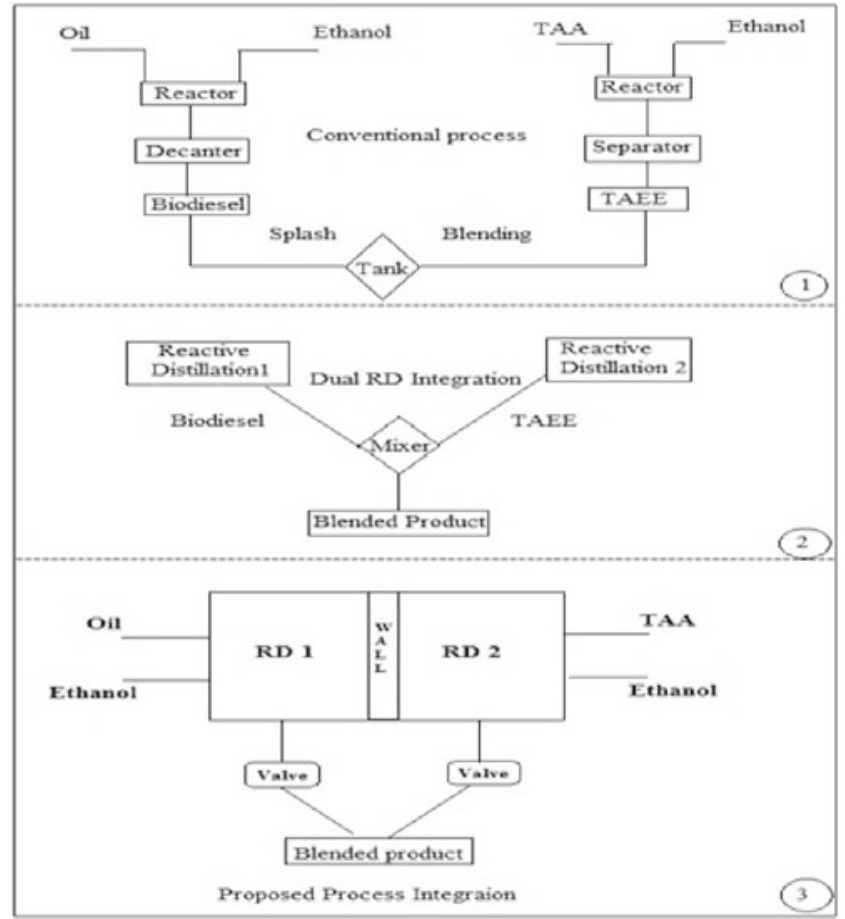

Figure 2. Alternative process approaches for biodiesel blending

part 2 in the same Figure. Finally, MRDW process is shown as part 3 in the same figure.

\section{Splash blending}

Pre-synthesized biodiesel is splash blended with TAEE oxygenate. The two were mixed in a tank through separate lines at high flow rates. This technique of blending is not adopted as a major drawback of it is insufficient blending. Also, accidents occur during hot seasons due to rise in temperature. This research work explores alternative blending techniques. Figure 2 shows splash blending of oil and ethanol in a conventional reactor to form biodiesel. TAA and ethanol reacts in a conventional reactor to form TAEE. Both these goes in a conventional separator such as the distillation column to separate biodiesel and TAEE from water. This follows the conventional splash blending of biodiesel from a decanter and TAEE from a separator.

\section{Dual RD integration technique}

The production of biodiesel requires excess alcohol, typically $100 \%$ excess, over its stoichiometric requirement to complete the chemical reaction. This excess alcohol must be recovered and purified for reusing by rectification and distillation, which involves additional capital and operating costs. Additional capital and costs are required to recover and purify the excess alcohol for reusing. Therefore, the combination of reactor and distillation in one single unit called reactive distillation leads to an enormous capital-investment cost reduction.

Table 2. Fuel property of pure and blended biodiesel

\begin{tabular}{|c|c|c|}
\hline Properties & B100 [Pure] & B20 [20\%biodiesel] \\
\hline Acid number [mm KOH/gm] & 0.50 & 0.30 \\
\hline Kinematic viscosity @ 104 ${ }^{\circ} \mathrm{F}\left[\mathrm{mm}^{2} / \mathrm{sec}\right]$ & $1.9-6$ & $1.9-4.1$ \\
\hline Flash point ${ }^{\circ} \mathrm{F}$ & 199.4 & 125 \\
\hline Cetane number & 47 & 42 \\
\hline Ash [\% mass] & 0.02 & 0.01 \\
\hline Water \& sediment [\% volume] & 0.05 & 0.05 \\
\hline
\end{tabular}


Table 3. Operating conditions for dual RD integration technique

\begin{tabular}{|c|c|c|}
\hline Parameters & Column 1(TAEE) & Column 2(biodiesel) \\
\hline Pressure & atmospheric & atmospheric \\
\hline Reboiler duty & $2 \mathrm{Kw}$ & $1.5 \mathrm{kw}$ \\
\hline Feed 1 temperature & $80^{\circ} \mathrm{C}(\mathrm{TAA})$ & $70^{\circ} \mathrm{C}$ (mustard oil) \\
\hline Feed 2 temperature & $50^{\circ} \mathrm{C}$ (ethanol) & $60^{\circ} \mathrm{C}$ ( methanol) \\
\hline Feed 1 flow rate & $\begin{array}{l}0.02 \mathrm{~L} / \mathrm{min} \\
\text { (top of reactive one) }\end{array}$ & $\begin{array}{l}0.04 \mathrm{~L} / \mathrm{min} \\
\text { (top of reactive zone) }\end{array}$ \\
\hline Feed 2 flow rate & $\begin{array}{l}0.02 \mathrm{~L} / \mathrm{min} \\
\text { (bottom of reactive zone) }\end{array}$ & $\begin{array}{l}0.025 \mathrm{~L} / \mathrm{min} \\
\text { (bottom of reactive zone) }\end{array}$ \\
\hline Total stakes & \multicolumn{2}{|r|}{10} \\
\hline Reflux ratio & \multirow{2}{*}{\multicolumn{2}{|c|}{$\frac{3}{0.5}$}} \\
\hline Boil up ratio & & \\
\hline Rectifying section & $1-3$ & $1-3$ \\
\hline Reactive zone & $3-6$ & $3-6$ \\
\hline Stripping section & $6-9$ & $6-9$ \\
\hline Condenser type & vertical & vertical \\
\hline Packing & \multicolumn{2}{|l|}{ Amberlyst 15 (in reactive zone) } \\
\hline Packing & \multicolumn{2}{|l|}{ Katapak S (in rectifying + strippig zone) } \\
\hline
\end{tabular}

This, makes reactive distillation as a part of process intensification is economical for equilibrium limited reversible reactions such as etherification of TAEE and transesterification for biodiesel production. Hence, in this paper, we have shown synthesis of both biodiesel and TAEE both using reactive distillation. As shown in Figure 3, the RD1 is used for synthesis of biodiesel and RD2 is used for synthesis of TAEE. The controlled flow rates from both the $\mathrm{RD} 1$ and $\mathrm{RD} 2$ is then passed to a mixer to get $\mathrm{B} 20(\%)$ blend. The operating condition and other details are summarized in Table 3.

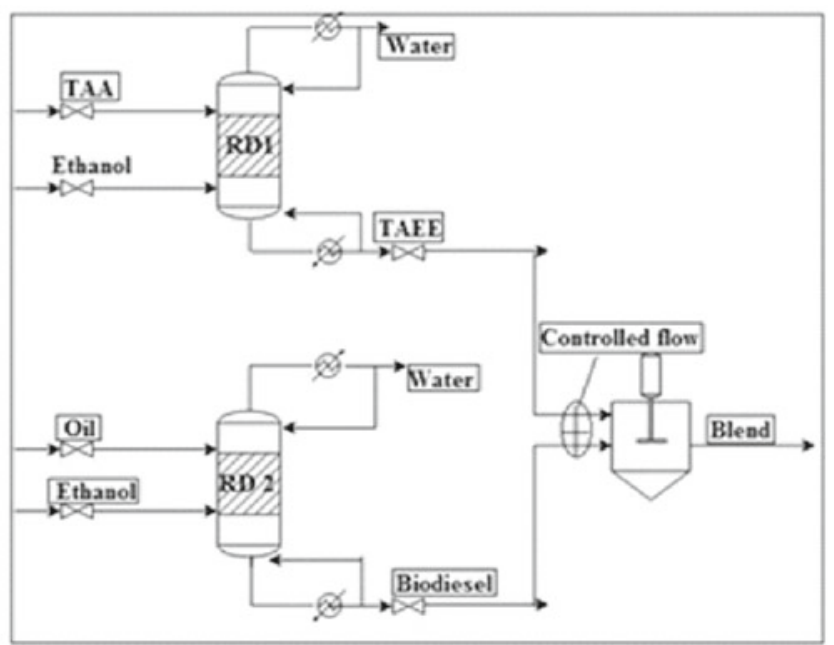

Figure 3. Schematic diagram of dual RD integration technique

\section{Membrane assisted reactive divided wall distillation process (MRDW)}

We have proposed a novel process integration concept in which we have used a divided wall column, which consist of a wall to the center of column composed of component selective membranes at the two sides. This saves the cost tremendously. Membranes have numerous numbers of useful properties such as, resistance to mechanical, chemical and thermal stress, high available surface area per unit volume, high selectivity, and the ability to control the components in contact. Inorganic membranes are preferred because of their ability to withstand harsh conditions such as higher temperatures, high acidic and basic environments. Commonly used membranes including metallic, ceramic, zeolite or carbon-made in reactive divided wall column. Literature shows that for biodiesel separation, carbon membrane is the most widely used while zeolite membrane is best suited for TAEE separation. Further, the colmn consists of 10 sections and is filled with amberlyst 15 in the middle i.e. from section three to six. Ethanol is the common reactant for biodiesel and TAEE synthesis. It is filled in the reboiler at the base so as to attain the temperature throughout the column. Oil is supplied from one side as a reactant for biodiesel synthesis on the top of the reactive zone while the Tert Amyl Alcohol (TAA) used for TAEE synthesis is supplied from the other side of the column. Another major advantage to this technique lies in the cost saving, as ethanol is not to be supplied continuously to the column, as it is filled in the reboiler at the base and is recycled continuously. The upcoming ethanol vapors are directed to both the sections in the column separted by the wall and react with downcoming oil in one section while with tert amyl alcohol at the other. The chemical reaction leads to the production of biodiesel and TAEE, which will be redirected to a collection vessel through a flow control valve. The paper envisaged to calculate the TAEE and biodiesel flow rate. The two were to be mixed in a proportion so as to achieve a target where final blend remains B20 (\%). The calculated \% biodiesel blend as obtained from MRDW is $19.7 \%$ which is within the legal limit.

The formula used for calculating biodiesel blend (\%) is given as:

Legal limit of biodiesel blend $=\left(\frac{\text { Molecular weight of the TAEE }}{\text { Molecular weight of the oxygen }}\right) *$ oxygen \% in blend

Further, biodiesel and TAEE produced were sent to the mixer to analyze the effect of blending of fuel with fuel oxygenate. Inline blending process was adopted where we can easily maintain the required blend grade by adjusting the biodiesel and TAEE flow rates.

\section{RESULTS AND DISCUSSION}

\section{Simulation studies}

\section{Simulation of dual integrated RD}

Steady state simulation studies were carried out using the Aspen Plus simulator. Firstly, the reactive distillation column is simulated by the module, Radfrac, using NRTL property method. Aspen plus requires the specification of components, property method, feed conditions (flow 
rate, composition and thermal state), operating pressure, column configuration (number of stages, feed location, reaction stage, types of condenser and reboiler), two operating parameters, and reaction type. The two operating parameters can be chosen from a set of parameters such as reflux ratio, distillate rate, bottoms rate, reboiler duty, condenser duty, etc. The reaction type can be chosen from kinetic, equilibrium and conversion.

The simulation was performed for biodiesel production using feed flow rate of $0.03 \mathrm{~L} / \mathrm{min}, 50^{\circ} \mathrm{C}$ temperature and $1 \mathrm{~atm}$ pressure for ethanol and $0.05 \mathrm{~L} / \mathrm{min}, 70^{\circ} \mathrm{C}$ temperature for oil. The specifications and other results of RDC are included in Table 4. The simulation flow sheet is shown in Figure 4. Simulation of TAEE using the same details as given in Table 3 was carried out. The composition profile obtained after simulation for TAEE and Biodiesel is shown in Figure 5 and 6 respectively. Figure 5 presents, the maximum composition of TAEE obtained as $82.6 \%$, while maximum composition of biodiesel obtained is almost $100 \%$, as shown in Figure 6.

The legal limit of biodiesel blend, to be within B20 (\%). We have calculated final blend of biodiesel with TAEE using flow rates of TAEE and Biodiesel. The flow rates of both fuels is controlled to maintain the blend range within B20 (\%). For this, we have used a flow rate of TAEE $28.30 \mathrm{Kg} / \mathrm{hr}$ and flow rate of Biodiesel as 116.20 $\mathrm{Kg} / \mathrm{hr}$, with final oxygen content of $2.7 \%$ to get the final blend of $19.6 \%$, which was within B20 (\%) limit. The flow rate of both fuels and \% blend is given in Table 5 .

Table 4. Input condition and results of RDC

\begin{tabular}{|l|c|c|}
\hline Parameters & \multicolumn{2}{|c|}{ Values } \\
\hline Input condition & Ethanol & Oil \\
\hline Temperature & $50^{\circ} \mathrm{C}$ & $70^{\circ} \mathrm{C}$ \\
Flow rate & $0.03 \mathrm{~L} / \mathrm{min}$ & $0.05 \mathrm{~L} / \mathrm{min}$ \\
\hline Reboiler heat duty & \multicolumn{2}{|c|}{$0.2 \mathrm{~kW}$} \\
\hline Reflux ratio & 5 \\
\hline Condenser Temperature & $57.40^{\circ} \mathrm{C}$ \\
\hline Condenser heat duty & $-0.54 \mathrm{~kW}$ \\
\hline Distillate rate & $10.56 \mathrm{~mole} / \mathrm{hr}$ \\
\hline Reflux rate & $52.81 \mathrm{~mole} / \mathrm{hr}$ \\
\hline Reboiler temperature & $62.66^{\circ} \mathrm{C}$ \\
\hline Bottom rate & $86.12 \mathrm{~mole} / \mathrm{hr}$ \\
\hline Boil up rate & $23.62 \mathrm{~mole} / \mathrm{hr}$ \\
\hline Boil up ratio & 0.274 \\
\hline
\end{tabular}

Table 5. Flow rates and final \% blend of biodiesel

\begin{tabular}{|l|r|}
\hline Parameters & Value \\
\hline Flow rate $[\mathrm{Kg} / \mathrm{hr}]$ & \\
TAEE & 28.30 \\
Biodiesel & 116.20 \\
\hline Target oxygen content & $2.7 \%$ \\
\hline TAEE \% in final blend & $19.6 \%$ \\
\hline
\end{tabular}

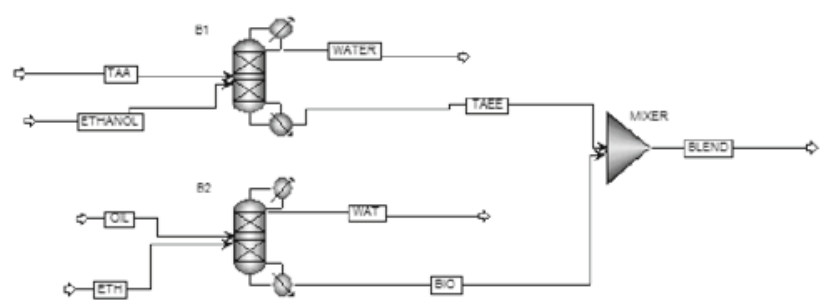

Figure 4. Simulation flow sheet of splash blending using dual RD

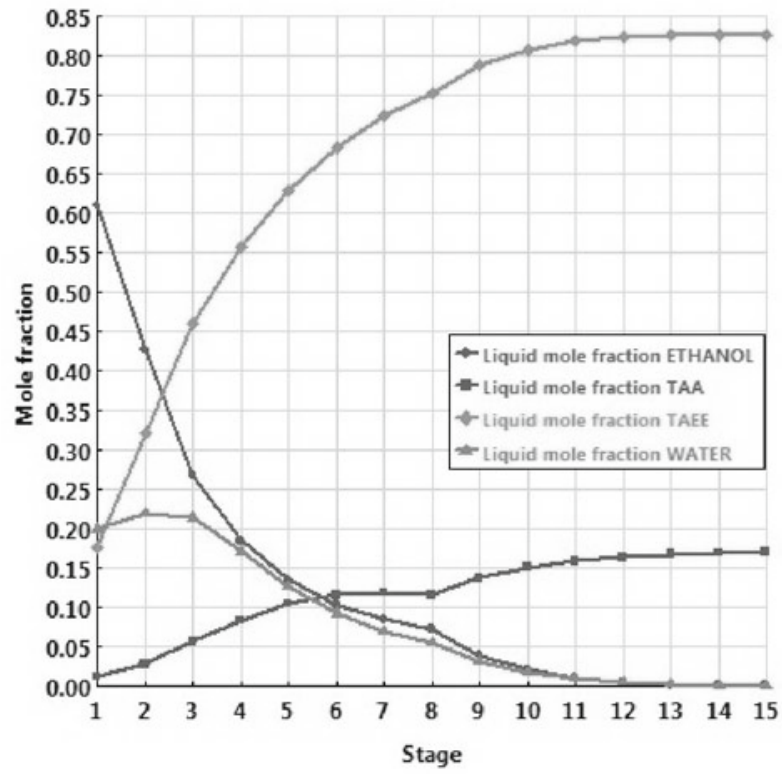

Figure 5. Composition profile of TAEE in column RD 1

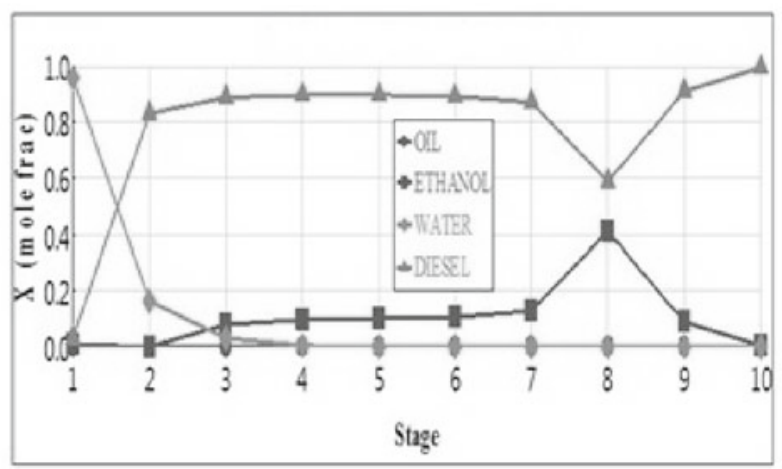

Figure 6. Composition profile for biodiesel in RD 2

\section{Simulation of membrane assisted RD}

Aspen plus is used to carry out simulation of membrane assisted reactive divided wall distillation column. The flow sheet of the same is shown in Figure 7. Two inlets from one side of the reactive divided wall, namely, oil and ethanol were passed to produce biodiesel using

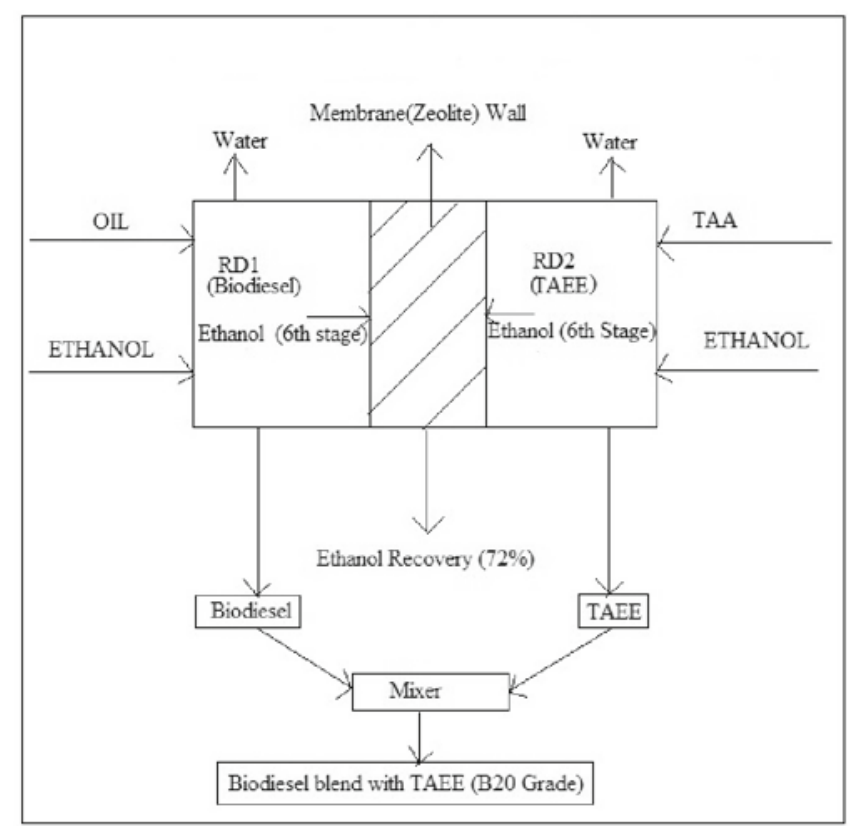

Figure 7. Proposed flow diagram of MRDW 
transesterification reaction, while TAA and ethanol as inlet passed through the other side of the divided wall column. The partitioning wall was made up of a membrane which is selective to the common reactant ethanol. Zeolite was used as membrane which is most suitable membrane for esterification reactions carried out in a reactive distillation column. After product formation, water as a byproduct from both the reactions was collected on top while, Biodiesel and TAEE was collected at the bottom. Maximum ethanol, which was recovered through the membrane was $72 \%$, which after collecting sufficient amount, can be recycled to reuse as a common reactant for both reactions. The composition profile of MRDW obtained after simulation is shown in Figure 8.

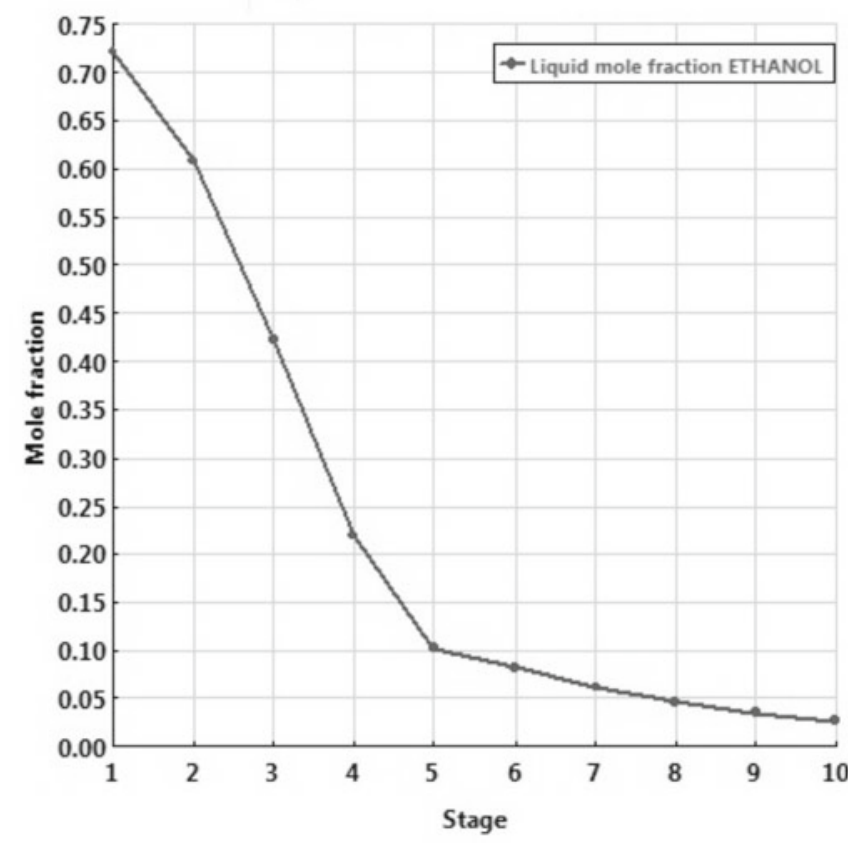

Figure 8. Composition profile of ethanol recovery through membrane

\section{Optimization results}

The sensitivity analysis was carried out to obtain the optimized value of input design variables corresponding to highest product purity. For biodiesel synthesis process boilup ratio and oil feed flow rate are important parameters for controlling the product purity, hence, these parameters are strictly optimized using a process simulator and the curves for optimized input parameters are shown in Figure 9 and 10 respectively. Figure 9 shows product purity is continuously increasing with

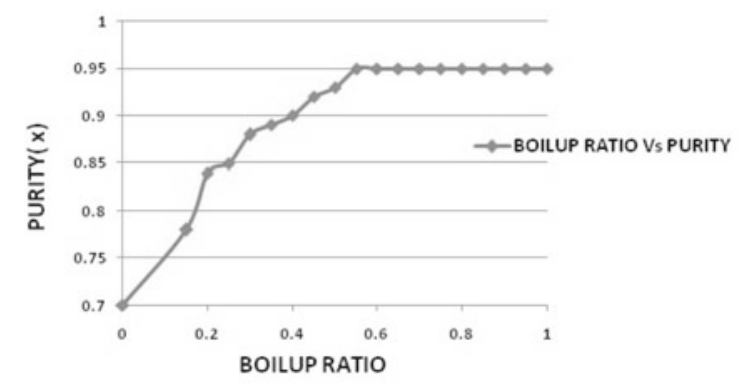

Figure 9. Optimization for biodiesel purity versus boil up ratio

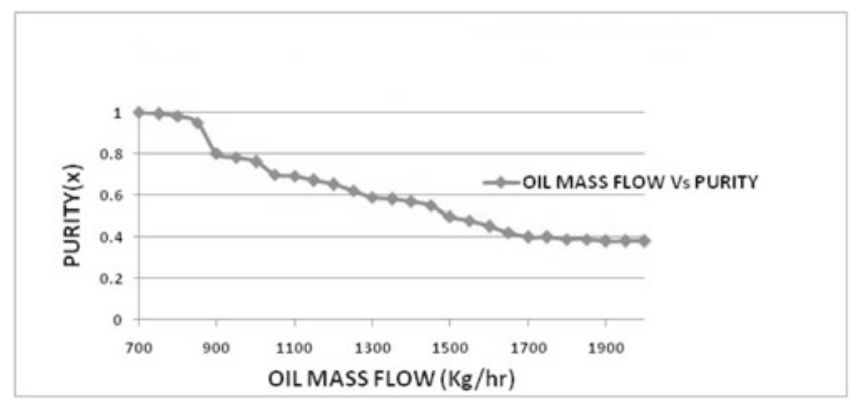

Figure 10. Optimization for biodiesel purity versus oil feed flowrate

increase in boil up ratio and it is constant after boil up ratio of 0.60 . Figure 10 presents, approximately $100 \%$ product purity is obtained at an oil mass flow rate of $700 \mathrm{~kg} / \mathrm{hr}$. As oil mass flow rate is increased purity is decreased. Therefore, the optimized boil up ratio is 0.65 and optimized oil mass flow rate is $700 \mathrm{~kg} / \mathrm{hr}$.

Similarly, for TAEE synthesis the sensitivity analysis is carried out by taking reboiler duty and reflux ratio as the critical parameters corresponding to highest product purity and the results are shown in Figure 11 and 12 respectively. As shown in Figure 11, the product purity is maximum at reboiler duty of 1200 watts, and further increase in reboiler duty, i.e. after 1400 watts, the purity is constantly below $30 \%$. Similarly, at a reflux ratio of 3.2 , the product purity is maximized, while a further increase in reflux ratio, results in a decrease in purity. Therefore, it is concluded that $1.2 \mathrm{~kW}$ is the optimized reboiler heat duty and 3.2 is the optimized reflux ratio.

A comparative outcome of dual RD integration technique and proposed MRDW

The dual RD integration leads to effective proportionate mixing of biodiesel with TAEE fuel oxygenate at the same time. However, there are many challenges

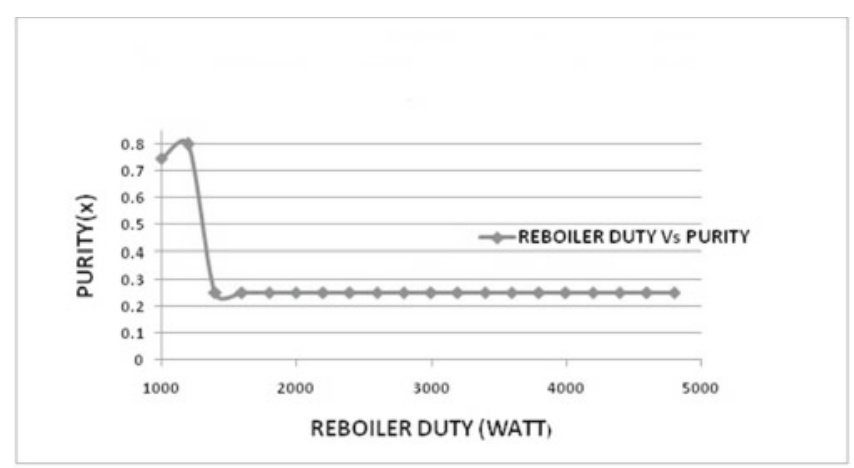

Figure 11. Optimization for TAEE purity versus reboiler duty

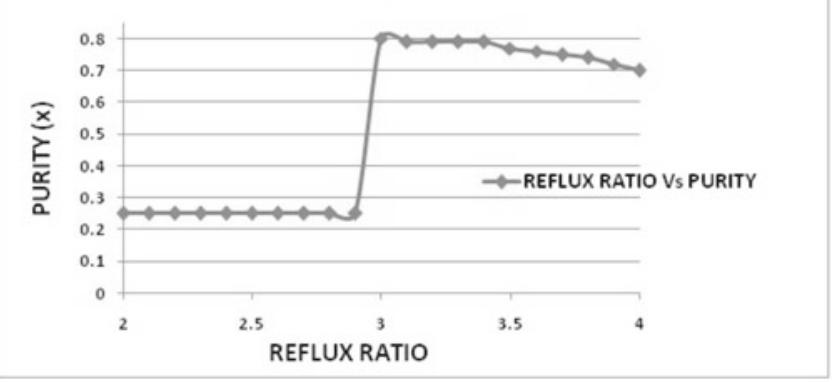

Figure 12. Optimization for biodiesel purity versus changes in reflux ratio 
Table 6. Comparative cost analysis of dual RD

\begin{tabular}{|l|c|c|}
\hline Name & Dual RD integration & Membrane assisted RDWC \\
\hline Total capital cost [USD] & 2742010 & 2096850 \\
\hline Total operating cost [USD/Year] & 957102 & 951126 \\
\hline Total utilities cost [USD/Year] & 36199.7 & 36008 \\
\hline Equipment cost [USD] & 47300 & 16700 \\
\hline Total installed cost [USD] & 272700 & 110200 \\
\hline Electricity [USD/H] & 4.062008 & 4.062008 \\
\hline Cooling water [USD/H] & 0.00504 & 0.004 \\
\hline Steam @100 psi [USD/H] & 0.062507 & 0.06210 \\
\hline
\end{tabular}

remaining with this process, such as high cost involved because of two separate reactive distillation column and each of which is equipped with its own reboiler, condenser that ultimately leads to high utility and run time cost. Further, since reactive distillation is highly nonlinear because of combination of reaction and separation, thus control of two simultaneous columns will require a higher skill operator and controller cost. The comparative cost analysis table is shown in Table 6 .

Comparatively, membrane assisted reactive divided wall distillation saves cost because of integration of two synthesis reaction into a single column. Divided wall is result into good turbulency which promote higher vapor liquid interaction and hence, higher product purity. This process also results in heat integration as only one reboiler and one condenser is needed. The main form of energy generator used in a distillation column, is reboiler, which directly affects the utilities cost such as, cooling water, electricity and steam. This reduction of energy demands diminishes the operating cost as per the reduction in utility cost. Another challenge faced in a reaction assisted separation is formation of azeotropes. Here since, both processes produces water as the top product which remains almost at temperature higher than $100^{\circ} \mathrm{C}$ i.e. above the boiling point, hence, there is no chance of azeotrope formation. Activation of the calculator block will evaluate the required flow rates of TAEE and biodiesel to be mixed in mixer to produce a blend under the legal limit.

\section{CONCLUSION}

In this research work, we have produced B20 (\%) TAEE blended biodiesel using process integration approach. After detailed optimized analysis and cost comparison of dual RD integration technique and Membrane Assisted Reactive Divided Wall (MRDW) column, we can conclude that, the latter process is a green process integration which involves better heat integration, better flow patterns and reduced cost. Since, two synthesis process and simultaneous separation occurs in single vessel we can say it is a novel process intensification. The attachment of a mixer with regulated flow control of biodiesel and TAEE leads to well a mixed, blended product within the legal limit of $19.7 \%$.

\section{ACKNOWLEDGEMENT}

The author gratefully acknowledges the financial assistance provided by All India Council of Technical Education (AICTE), New Delhi, in the form of RPS project.

\section{LITERATURE CITED}

1. Singh, A.P., Thompson, J.C. \& Brian, He B. (2004). A Continuous flow Reactive Distillation Reactor for Biodiesel Preparation from Seed oils, Can. Soc. Engineer. Agric., Food Biol. Syst. 1-11. DOI: 10.7451/CBE.2004.

2. Serio, M. De., Tesser, R. \& Pengmei, Lu. (2008). Heterogeneous catalyst for biodiesel production. Ener. Fuel. 22, 207-217. DOI: 10.1021/ef700250g.

3 Kiss, A.A., Dimian, A.C. \& Rothenberg, G. (2008). Biodisel by Catalytic Reactive Distillation Powered by Metal Oxides, Ener. Fuel. 22, 598-604. DOI: 10.1021/ef700265y.

4. Atadashi, I.M., Aroua, M.K., Abdul, A.R. \& Sulaiman, N.M.N. (2011). Membrane biodiesel production and refining technology: A critical review. Renew. Sustain. Rev. 5051-5062. DOI: 10.1016/j.rser.2011.07.051.

5. Aiouache, F. \& Goto, S. (2003). Reactive Distillationpervaporation hybrid column for tert-amyl alcohol etherification with ethanol. Chem. Engineer. Sci. 28, 2465-2477. DOI: 10.1016/s0009-2509(03)00116-7.

6. Steinigweg, S. \& Gmehling, J. (2004). Transesterification process by combination of reactive distillation and Pervaporation. Chem. Engineer. Proces. 43, 447-456. DOI: 10.1016/ s0255-2701(03)00129.6.

7. Liu, K., Tong, Z., Liu, Li. \& Feng, X. (2005). Separation of organic compounds from water by pervaporation in the production of $\mathrm{n}$ butyl acetate via esterification by reactive distillation, J. Membr. Sci. 256, 193-201. DOI: 10.1016/j. memsci.2005.02.020.

8. He, B.B., Singh, A.P. \& Thompson, J.C. (2005). Experimental Optimization of a Continuous Flow reactive distillation Reactor for Biodiesel Production. Am. Soc. Agric. Engin. 48, 2237-2243.

9. He, B.B., Singh, A.P. \& Thompson, J.C. (2006). A Novel Continuous Flow Reactor Using Reactive Distillation For Biodiesel Production, Am. Soc. Agric. Engin. 49, 107-112.

10. Israel, F., Gomez-castro, Ramirez, V.R., Hernandez, J.G.S. \& Hernandez, S. (2010). Feasability study of a thermally coupled reactive distillation process for biodiesel production, Chem. Engineer. Proces. 49, 262-269. DOI: 10.1016/j.cep.2010.02.002.

11. Wang, S.J., Wong, D.S.H. \& Yu, S.W. (2008). Design and control of transesterification reactive distillation with thermal coupling. Comput. Chem. Engineer. 32, 3030-3037. DOI: 10.1016/j.compcheneng.2008.04.001.

12. Silva, N.D.L.D., Satander, C.M.G. \& Batistella, C.B. (2010). Biodiesel Production from Integration between Reaction and Separation System: Reactive Distillation Process. Appl. Biochem. Biotechnol. 161, 245-254. DOI: 10.1007/s/2010-009-8882-7.

13. Simasattikul, L., Sricharansakunchai, P., Patcharvorachot, Y., Assabumrungrat, S. \& Arpornwichanop, A. (2011). Reactive Distillation for Biodiesel Production from Soyabean oil. Korean J. Chem. Engineer. 28, 649-655. DOI: 10.1007/s/11814010-0440-z.

14. Demirel, Y. (2011). Using Thermally Coupled Reactive Distillation Columns in Biodisel Production. Chem. Biomolec. Res. Pap. 36, 838-4847. DOI:10.1016/j.energy.2011.05.020.

15. Rios, L.F., Martinez, E.L., Silva, N.L., Dantas, T.S.S., Maciel, R. \& Maciel, M.R.W. (2012). Biodiesel Production by an 
Integrated Reactive Separation System: A Comparative Study. Chem. Engineer. Trans. 26, 255-260. DOI: 10.3303/CET1226043.

16. Budiman, A. (2012). A step toward industrial plant of continuous Biodiesel production using reactive distillation process. Int. J. Environ. Bioen., 3, 180-192.

17. Kiss, A.A., Gabriel, J., Hernandez, S., Bildea, C.S., Galindo, E.Y.M. \& Hernandez, S. (2012). Reactive DWC leading the way to FAME and fortune. Fuel. 95, 352-359. DOI: 10.1016/j.fuel.2011.12.064.

18. Kiss, A.A. \& Ignat, R.M. (2012). Enhanced methanol recovery and glycerol separation in biodiesel production-DWC makes it happen. Appl. Energy. 99, 146-153. DOI: 10.1016/j. apenergy.2012.04.019.

19. Kiss, A.A. \& Suszwalak, D.J.P.C. (2012). Enhanced bioethanol dehydration by extractive and azeotropic distillation in dividing-wall columns. Separat. Purificat. Technol. 86, 70-78. DOI:10.1016/j.seppur.2011.10.022.

20. Chongkhong, S., Tongurai, C. \& Chepattananondh, P. (2009). Continuous esterification for biodiesel production from palm fatty acid distillate using economical process. Renew.Ener. 34, 1059-1063. DOI: 10.1016/j.renene.2008.07.008.

21. Castro, F.I.G., Ramirez, V.R., Hernandez, J.G.S., Castro, S.H. \& Halwagi, M.M. El. (2013). Simulation study on biodiesel production by reaction distillation with methanol at high pressure and temperature: Impact on costs and pollutant emissions. Comput. Chem. Engineer. 52, 204-215. DOI: 10.1016/j. comchemeng.2013.01.007.

22. Cossio-Vargas, E., Hernandez, S., Segovia-Hernandez, J.G. \& Cano-Rodriguez, M.I. (2011). Simulation study of production of biodiesel using feedstock mixtures of fatty acids in complex reactive distillation columns. The Ener. J. 36, 6289-6297. DOI: 10.1016/j.energy.2011.10.005.

23. Cossio-Vargas, E., Munoz, F.O.B., Hernandez, S., Hernandez, J.G.S. \& Rodriguez, M.I.C. (2012). Thermally coupled distillation sequences: Stea Arief Budiman, A step toward industrial plant of continuous Biodiesel production using reactive distillation process. Int. J. Environ. Bioener. 3, 180-192.

24. Giwa, A. \& Giwa, S.O. (2012). Optimization of Tranesterification Reaction Integrated Distillation Column Using Design Expert and Excel Solver. Int. J. Adv. Sci. Tech. Res. 6, 423-435. 